\title{
Accelerometer-based Physical Activity Monitoring in Patients with Knee Osteoarthritis: Objective and Ambulatory Assessment of Actual Physical Activity During Daily Life Circumstances
}

\author{
L. Verlaan, S.A.A.N. Bolink ${ }^{*}$, S.N. Van Laarhoven, M. Lipperts, I.C. Heyligers, B. Grimm and \\ R. Senden
}

AHORSE Foundation, Department of Orthopaedics, Atrium Medical Center Heerlen, The Netherlands

\begin{abstract}
Background: It is important to assess physical activity objectively during daily life circumstances, to understand the association between physical activity and diseases and to determine the effectiveness of interventions. Accelerometer-based physical activity monitoring seems a promising method and could potentially capture all four FITT (i.e. Frequency, Intensity, Time, Type) components of physical activity considered by the World Health Organization (WHO).

Aim: To assess the four FITT components of physical activity with an accelerometer during daily life circumstances and compare with self-reported levels of physical activity in patients with knee osteoarthritis (OA) and a healthy control group.

Methods: Patients $(\mathrm{n}=30)$ with end-stage knee OA and age-matched healthy subjects $(\mathrm{n}=30)$ were measured. An ambulant tri-axial accelerometer was placed onto the lateral side of the upper leg. Physical activity was measured during four consecutive days. Using algorithm-based peak detection methods in Matlab, parameters covering the four FITT components were assessed. Self-reported physical activity was assessed using the Short questionnaire to assess health enhancing physical activity (SQUASH).

Results: Knee OA patients demonstrated fewer walking bouts (154 \pm 79 versus $215 \pm 65$ resp.; $\mathrm{p}=0.002$ ), step counts (4402 \pm 2960 steps/day versus $6943 \pm 2581$ steps/day; $\mathrm{p}=0.001)$ and sit-to-stand (STS) transfers $(37 \pm 14$ versus $44 \pm 12 ; \mathrm{p}=0.031)$ compared to controls. Knee OA patients demonstrated more time sitting ( $65 \pm 15 \%$ versus $57 \pm 10 \%$ resp.; $p=0.029)$, less time walking ( $8 \pm 4 \%$ versus $11 \pm 4 \%$ resp.; $\mathrm{p}=0.014)$ and lower walking cadence $(87 \pm 11 \mathrm{steps} / \mathrm{min}$ versus $99 \pm 8$ steps $/ \mathrm{min}$ resp.; p $<0.001)$. Accelerometer-based parameters of physical activity were moderately-strong (Pearsons's $r=0.28-0.49)$ correlated to self-reported SQUASH scores.
\end{abstract}

Conclusion:_A single ambulant accelerometer-based physical activity monitor feasibly captures the four FITT components of physical activity and provides more insight into the actual physical activity behavior and limitations of knee OA patients in their daily life.

Keywords: Accelerometer, activity monitor, FITT, knee osteoarthritis, physical activity.

\section{INTRODUCTION}

Physical activity is an important determinant of general health and is negatively affected by many chronic degenerative diseases $[1,2]$. To understand the association between physical activity and diseases, and to determine the effectiveness of interventions, it is crucial for clinicians and researchers to assess and monitor physical activity during daily life circumstances [3]. Various studies have demonstrated that physical activity programs convey general health benefits and improve disease-related symptoms and complications, such as pain, fatigue and functional limitation

*Address correspondence to this author at the AHORSE Foundation, Department of Orthopaedics, Atrium Medical Center Heerlen, the Netherlands, Henri Dunantstraat 5, 6419PC, Heerlen, The Netherlands; Tel: +31655341492; E-mail: stijn.bolink@mail.com
[4]. Monitoring physical activity to provide individual feedback could therefore be an essential part of a wide spectrum of applications [3, 5], including patients with cardiovascular diseases, neurodegenerative diseases (e.g. Parkinson's disease) and knee osteoarthritis (OA) [6]. Assessment of physical activity is traditionally employed by self-report questionnaires. These questionnaires are inexpensive and easy to use in clinical practice, however due to subjectivity they are prone to overestimation and may not reflect actual physical activity [4, 7]. Moreover, self-report questionnaires do not have the potential to assess all four components of physical activity considered by the World Health Organization (WHO): Frequency, Intensity, Time and Type (abbreviated FITT) [2, 8]. Current guidelines for physical activity may be realistic and reasonable for selfreported physical activity, however it is not clarified yet what levels of objectively assessed physical activity are 
reasonable and associated with health benefits. Reports in literature have demonstrated that with self-reported assessment of physical activity, up to $62 \%$ of the general population meet the activity intensity guidelines whereas only $9.6 \%$ meet these same guidelines when defined from objective physical activity monitoring [9].

The current gold standard method to objectively assess free-living physical activity is the doubly labeled water method (DLW), which involves the ingestion of water labelled with stable isotopes ${ }^{2} \mathrm{H}$ and ${ }^{18} \mathrm{O}$ [10]. As energy is expended in the body, $\mathrm{CO}_{2}$ and $\mathrm{H}_{2} \mathrm{O}$ are produced, and the differences between the isotope elimination rates are used to calculate total energy expenditure. Although DLW is a very precise and accurate method to assess energy expenditure [11], it is not feasible for routine use and it does not allow assessment of physical activity by the four FITT components. Developments in ambulant motion sensor technologies have recently provided more feasible alternatives for objective assessment of actual free-living physical activity [2, 12]. These ambulant activity monitors (AMs) have evolved considerably over the years from simple pedometers to AMs equipped with heart rate monitors, GPS trackers and accelerometers [3]. Validation studies of methods for the assessment of physical activity have shown that accelerometry is superior to self-report questionnaires and heart rate monitoring compared to $\operatorname{DLW}[1,13]$. Moreover, accelerometry has demonstrated its potential to provide an estimation of activity quantity [13], to provide qualitative assessment of physical activity such as spatiotemporal gait analysis [9] and activity intensity measures [12]. Furthermore, accelerometer-based physical activity monitoring permits to differentiate between different activities of daily living (ADL) such as walking or sitting [5, 14] and could select only those activities that are challenging and clinically relevant for specific patient populations. Therefore, accelerometer-based physical activity monitoring is currently the most widely used method to objectively assess physical activity in daily life circumstances and could potentially capture all four FITT components of physical activity.

The primary aim of this study was to investigate the potential of ambulant accelerometer-based physical activity monitoring to objectively assess the four FITT components of physical activity during daily life circumstances. A second aim of the study was to apply accelerometer-based physical activity monitoring in a physically impaired population of patients with advanced knee OA, and to compare their levels of physical activity to an age-matched healthy control group. A third aim of the study was to compare objectively assessed levels of physical activity by an ambulant accelerometer to subjective self-reported levels of physical activity assessed by a questionnaire.

\section{MATERIALS \& METHODS}

\section{Participants}

Patients $(n=30)$ with end-stage knee OA (KellgrenLawrence scale 3-4) that were listed for a total knee replacement (TKR) at the outpatient clinic, were approached and asked to participate. An age-matched healthy control group $(n=30)$ was used for comparison (Table 1). All participants were informed about the study prior to participation and oral informed consent was obtained. Ethical approval for testing the participants was obtained by the Medical Ethics Committee (METC) of the Atrium Medical Centre Heerlen, The Netherlands, with METC number: 10-N-72. Healthy participants had no joint pain and no medical history of lower extremity joint surgery. Knee $\mathrm{OA}$ patients were excluded when there was a presence of $\mathrm{OA}$ in the contralateral knee for which a TKR would be indicated, when they were wheelchair-bound and if they were not living independently. Exclusion criteria for the control group were the presence of a musculoskeletal or neurological disorder, or any previous surgical intervention that could affect the level of actual physical activity. All participants were asked to behave according to their normal habits during the physical activity monitoring.

\section{Physical Activity Monitor (AM)}

A commercially available, small (dimensions: $64 \times 25 \times 13 \mathrm{~mm}$ ) and light-weight (weight $18 \mathrm{~g}$ ) tri-axial accelerometer (GCdataconcepts, US) was used as activity monitor (AM). Battery life of the AM is sufficient to measure seven consecutive days of activities. The AM was attached onto the lateral side of the non-affected upper leg, using hypo-allergenic double sided tape (Fig. 1). Twelve bit data (range $\pm 2 \mathrm{~g}$ ) was collected at a sampling rate of $40 \mathrm{~Hz}$ and stored on an on-board memory micro-SD card. The raw acceleration signal was analyzed using the inclinometer function of the accelerometer and algorithm-based peak

Table 1. Participants' demographics demonstrating significant differences for body mass and body mass index (BMI) between the knee OA group and control group.

\begin{tabular}{|c|c|c|c|c|}
\hline & \multicolumn{2}{|c|}{ Knee OA group n=30 } & \multicolumn{2}{c|}{ Control group n=30 } \\
\hline & Mean \pm SD & Mean \pm SD & $16 / 14$ & $($ range $)$ \\
\hline \hline Male/female & $11 / 19$ & & $67.3 \pm 8.4$ & $(56-89)$ \\
\hline Age (years) & $68.7 \pm 6.9$ & $(56-81)$ & $171.7 \pm 8.0$ & $(156-190)$ \\
\hline Height $(\mathrm{cm})$ & $169.3 \pm 12.3$ & $(149-191)$ & $74.4 \pm 13.2$ & $(50-104)$ \\
\hline Body mass $(\mathrm{kg})$ & $86.6 \pm 19.1^{*}$ & $(52-125)$ & $24.7 \pm 3.4$ & $(19-32)$ \\
\hline BMI $\left(\mathrm{kg} / \mathrm{m}^{2}\right)$ & $29.6 \pm 5.7^{* *}$ & $(21-42)$ & & $(2.4)$ \\
\hline
\end{tabular}

$* \mathrm{p}<0.01 ; * * \mathrm{p}<0.001$. 
detection methods in Matlab, based on previously published principles $[15,16]$. Briefly, calibration of the accelerometer's orientation is performed within a period of level walking that is manually selected. Within this walking period, the average magnitudes of the three acceleration vectors and the gait cycle frequency $(\mathrm{GCF} ; \mathrm{Hz})$ are derived to allow further differentiation between activities. Differentiation between standing periods and sitting periods is based on the direction of the gravitation vector and allows identification of sit-to-stand (STS) transfers. Walking is differentiated from other upright activities (all classified as standing) by application of heuristic rules to the GCF. A walking period is classified when at least 5 consecutive heel strike peaks are detected, with $<1.5$ seconds between peaks for a $\mathrm{GCF}>0.6 \mathrm{~Hz}$ and $<3.0$ seconds between peaks for a $\mathrm{GCF}<0.6 \mathrm{~Hz}$. This algorithm allows activities and postures to be differentiated and counted, to derive frequency measures (\# steps/day, \# walking bouts/day, \# sit-to-stand transfers/day), to determine the time or duration of these activities (expressed as \% of the total measured time) and type of activity (sitting, standing, walking) can be identified. Besides quantitative parameters, qualitative parameters can be derived such as walking intensity (cadence (step/min)) and the distribution of activities (e.g. short $(<5 \mathrm{~min})$ versus long ( $>5 \mathrm{~min})$ walking bouts). These parameters cover all four FITT components (Frequency, Intensity, Time and Type) of physical activity considered by the WHO.

Physical activity was measured during four successive days as previous studies have shown that three to four days of activity monitoring are required to characterize an individual's habitual physical activity pattern $[17,18]$. The $\mathrm{AM}$ was worn only during waking hours with a minimum of 8 hours a day and removed at night.

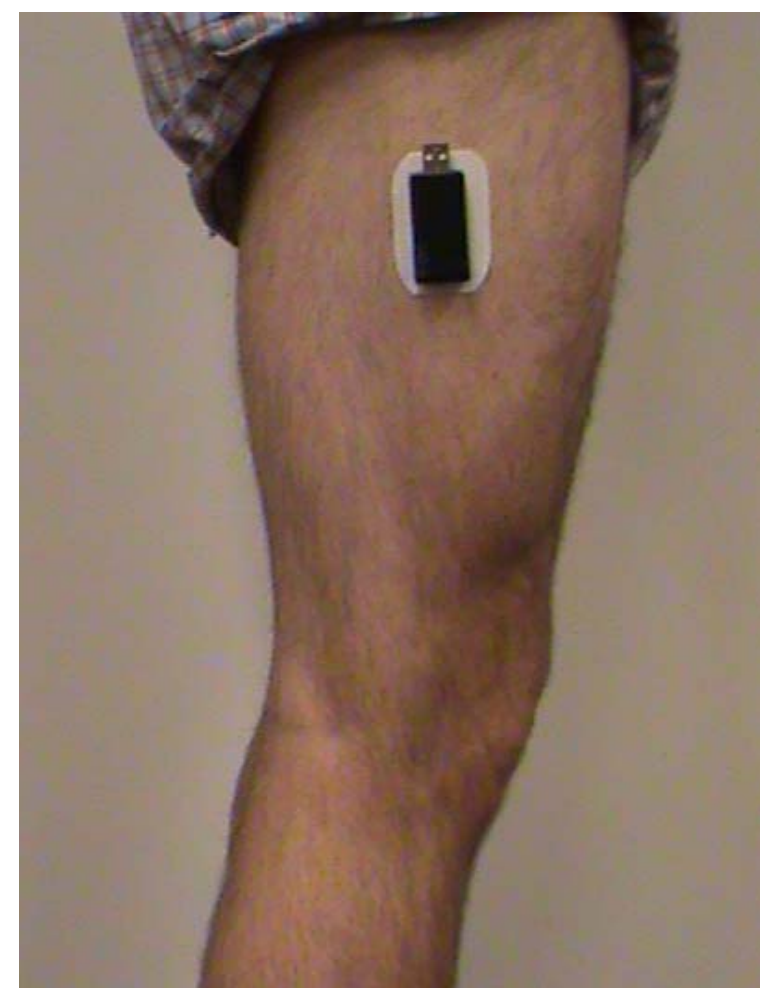

Fig. (1). AM position.

\section{Self-report Questionnaires}

Perceived physical activity was measured using the Short questionnaire to assess health enhancing physical activity (SQUASH) which assesses habitual physical activity during a normal week over the past few months $[19,20]$. Total score is expressed in minutes of physical activity per week [21].

\section{Statistical Analysis}

Statistical analyses were performed using IBM SPSS statistics. First data were explored for normal distribution using the Kolmogorov-Smirnov test. Results were presented as means with standard deviations (SDs) and their range. Differences between the knee OA group and control group were evaluated by an independent-samples T-test. The association between groups' demographic variables and outcomes of AM parameters was investigated with linear regression analysis, demonstrating the level of significance (p-value) and the degree of the association expressed by the partial correlation coefficient. The association between AM parameters and self-reported physical activity score assessed by the SQUASH questionnaire was calculated with Pearson's $r$ correlation coefficient.

\section{RESULTS}

The two groups showed no significant differences in age ( $68.7 \pm 6.9$ yrs vs. $67.3 \pm 8.4$ yrs $)$ and height $(169.3 \pm 12.3$ yrs vs. $171.7 \pm 8.0 \mathrm{yrs})$, however the knee OA group demonstrated a significantly higher body mass index (BMI; $\mathrm{kg} / \mathrm{m}^{2}$ ) than the control group (BMI= 29.6 \pm 5.7 versus 24.7 $\pm 4.3 ; \mathrm{p}<0.001$ ). In the knee OA group, $37 \%$ was male whereas in the control group 53\% was male (Table 1). Linear regression analysis demonstrated that the difference in BMI between groups had a significant influence on the time spent sitting (partial correlation coefficient $=0.37 ; \mathrm{p}=0.017$ ) and the amount of walking bouts <1min (partial correlation coefficient $=0.34 ; \mathrm{p}=0.027$ ).

The knee OA group recorded physical activity during an average of $12.7 \pm 1$.8hours/day which was significantly less than the healthy control group recording $13.6 \pm 1$.3hours/day $(\mathrm{p}=0.03)$. Considering the four FITT components of physical activity, the knee OA group was less active than the control group on all components. The frequency of walking bouts ( $154 \pm 79$ versus $215 \pm 65$ resp.; $\mathrm{p}=0.002)$, step counts (4402 \pm 2960 steps/day versus $6943 \pm 2581$ steps/day; $p=0.001)$ and sit-to-stand (STS) transfers $(37 \pm 14$ versus $44 \pm 12 ; \mathrm{p}=0.031)$ was significantly less in knee OA patients compared to controls (Table 2). Walking intensity was significantly less for knee OA patients compared to controls, considering walking cadence $(87 \pm 11$ steps/min versus $99 \pm 8$ steps $/$ min resp.; $\mathrm{p}<0.001)$ and considering the duration of walking bouts with a larger percentage of short $(<1 \mathrm{~min}$ and $<5 \mathrm{~min})$ walking bouts found in knee OA patients (Table 2). Time (i.e. duration) and type of activity distribution demonstrated significantly less time walking for the knee OA group compared to the control group ( $8 \pm 4 \%$ versus $11 \pm 4 \%$ resp.; $\mathrm{p}=0.014)$ and significantly more time sitting $(65 \pm 15 \%$ versus $57 \pm 10 \%$ resp.; $\mathrm{p}=0.029$ ). In addition, knee OA patients demonstrated fewer short $(<1 \mathrm{~min})$ sitting events compared to healthy controls $(8 \pm 3$ versus $13 \pm 7$ resp.; $\mathrm{p}=0.002)$ but similar long (>5min) sitting events $(29 \pm 13$ versus $33 \pm 8 ; p>0.05$ ). 
Self-perceived physical activity also demonstrated less physical activity for patients with knee OA compared to the control group. SQUASH scores were significantly lower for knee OA patients $(3085 \pm 2236 \mathrm{~min}$ versus $5314 \pm 2876 \mathrm{~min}$ resp.; $\mathrm{p}=0.005)$. SQUASH scores demonstrated moderate correlations with quantitative AM parameters: bouts walking $(r=0.49 ; p<0.001)$, step counts $(r=0.36 ; p=0.008)$, percentage time sitting $(\mathrm{r}=-0.44 ; \mathrm{p}=0.001)$, percentage time walking $(\mathrm{r}=0.33 ; \mathrm{p}=0.014)$, percentage time standing $(\mathrm{r}=0.42$; $\mathrm{p}=0.002$ ) and to the qualitative AM parameters: walking bouts <1min ( $\mathrm{r}=0.46$; $\mathrm{p}<0.001)$, walking bouts $1-5 \mathrm{~min}$ $(\mathrm{r}=0.45 ; \mathrm{p}=0.001)$ and amount of short sitting events $(\mathrm{r}=0.28$; $\mathrm{p}=0.039)$.

Table 2. Outcome for accelerometer-based physical activity monitoring, demonstrating mean values per day and comparing results for knee $\mathrm{OA}$ patients with a control group.

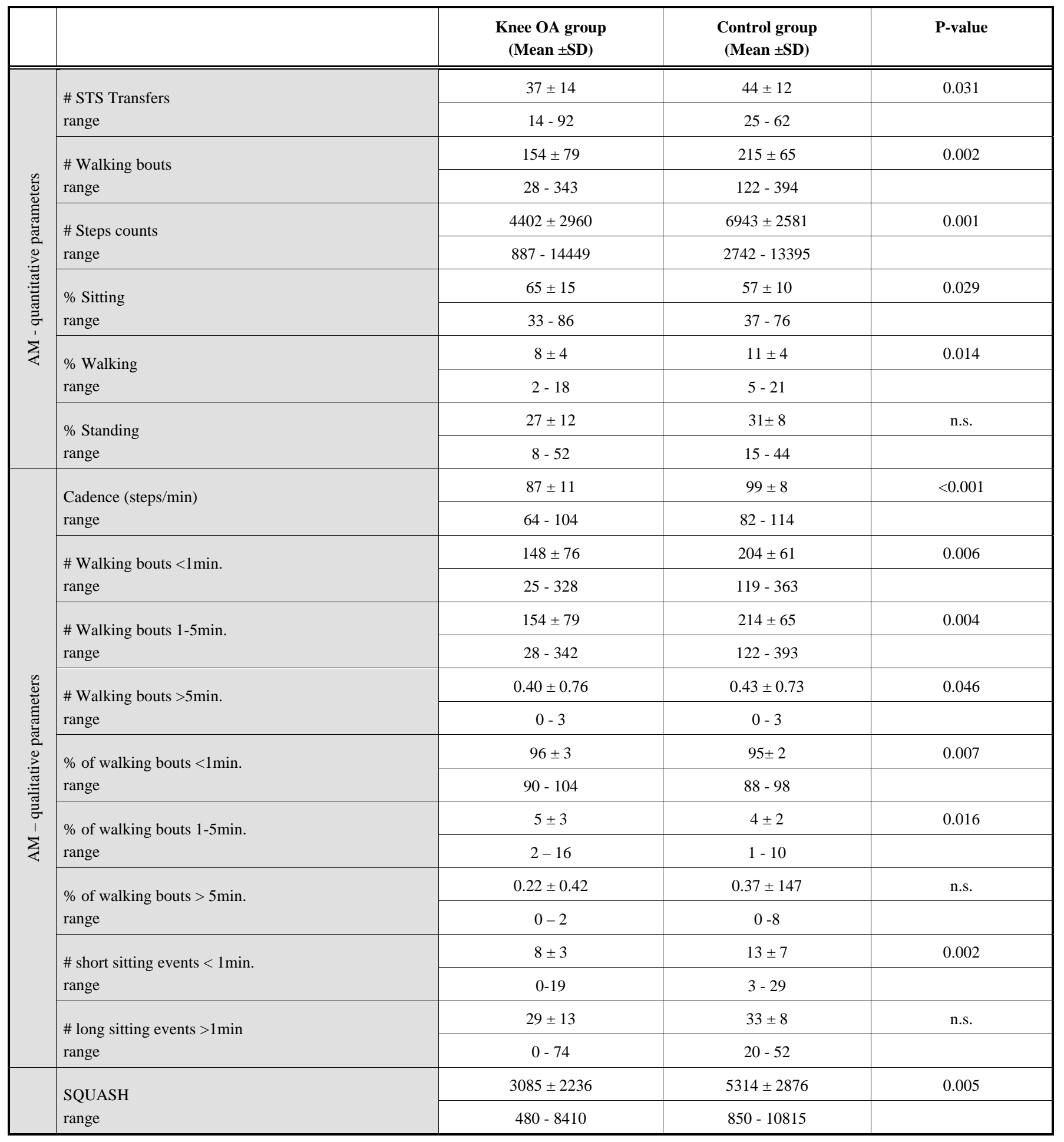




\section{DISCUSSION}

This study demonstrates that an ambulant accelerometerbased physical activity monitor allows objective assessment of the four FITT components of physical activity during daily life circumstances. Frequency, Intensity, Time and Type (FITT) of physical activity in patients with advanced knee OA were significantly different to an age-matched healthy control group. Accelerometer-based levels of actual physical activity were moderately (Pearsons's $r=0.28-0.49$ ) correlated to self-reported levels of perceived physical activity. This could suggest that both methods partially overlap in the domain of physical activity but also capture different aspects of physical activity. These findings might also explain discrepancies that have been found between self-reported and objectively assessed levels of physical activity required to meet current recommended physical activity guidelines [4, 9, 22, 23].

Knee osteoarthritis (OA) is a degenerative disease associated with functional impairments and physical activity limitations which deteriorate slowly over time. Patients with knee OA suffer from pain, joint stiffness and reduced muscle strength, and have difficulties in many daily life activities [24], including walking, rising from a chair and stair climbing [25]. Patients with knee OA tend to avoid physical activity in order to prevent pain and may believe physical activity is harmful to their joint [23] whereas this passive coping style is a risk factor for future limitations in activities [24]. Restriction of physical activity reported by patients affects their quality of life and could be indicative for total knee replacement surgery [14]. Findings of this study confirm validity of the avoidance model as explanation for deterioration of physical activity limitations in patients with knee OA, considered by the four FITT components of physical activity [24]. Knee OA patients demonstrated less activity frequency expressed by the amount of STS-transfers, walking bouts and step counts; lower activity intensity expressed by lower walking cadence and fewer long ( $>5 \mathrm{~min}$ ) walking bouts; less activity time expressed by the lower percentage of time spent walking; and the distribution of the type of activity demonstrated a more sedentary lifestyle for knee OA patients. Despite lack of physical activity and exercise, a sedentary lifestyle alone has negative effects on health indices [26]. Historically, physical activity was believed to increase risk of knee OA. However, it is now recognized to improve muscle strength, reflex inhibition, proprioception, and range of motion in the knee and decrease the risk of excess weight gain [22]. Therefore, regular exercises and other structured activities have a favorable effect on pain and function and form a safe, multifaceted therapeutic treatment to improve health and many of the factors that lead to disability in the sedentary knee OA patient [27].

Findings of the current study are in accordance to the few previous published studies that compared levels of physical activity between patients with end-stage knee OA and healthy persons $[4,14,22,28]$. A study by de Groot et al. [14] compared accelerometer-based physical activity levels in 44 patients with knee OA to healthy controls. They also found a significant higher BMI $(32.1 \pm 5.8)$ in knee OA patients compared to the control group $(26.8 \pm 3.8)$, which was significantly related to the percentage of movement- related activity. In their study population, knee OA patients demonstrated less STS transfers ( $46 \pm 14$ versus $61 \pm 23$ ) and spent less time walking $(6 \pm 3 \%$ versus $9 \pm 3 \%)$. Comparing their outcomes with our results, we found slightly less STS transfers for knee OA patients $(37 \pm 14)$ and healthy controls $(44 \pm 12)$. Furthermore knee OA patients $(8 \pm 4 \%)$ spent slightly more time walking compared to healthy controls (11 $\pm 4 \%$ ). The rather small differences with our study results might be explained by the methods that were used to assess physical activity. De Groot $e t$ al. assessed physical activity with four AMs during 48 consecutive hours whereas in the current study, one AM was used and worn during four consecutive days only during waking hours, resulting in an average assessment time of \pm 13 hours/day. Another study [28] assessing physical activity in 25 patients with end-stage knee OA, using a bi-axial accelerometer armband, found significantly less steps/day compared to a healthy control group (6625 \pm 2970 versus \pm 8576 2872) which was negatively influenced by BMI. Besides the use of a different type of AM, physical activity was monitored during $24 \mathrm{~h} /$ day which could explain absolute differences for step counts found in the current study. Therefore, a limitation of this study is that participants were allowed to remove the AM during a substantial part of the day. Thus we cannot feasibly compare absolute activity numbers (e.g. step count, STStransfers, walking bouts) with results from literature and current physical activity guidelines. However, in a study by Farr et al. [22] knee OA patients were also instructed to wear the accelerometer during all waking hours which resulted in a recording time of $13.8 \pm 2.2$ hours/day, comparable to the recording time of $12.7 \pm 1$.8hours/day in the current study. Another issue for concern is the type of AM used and its location. An AM should theoretically be located near the body's centre of mass to reflect movements of the total body [1]. Alternatively, AMs can be attached to locations of the body where they would register the most activity (e.g. the legs during walking) or to a location with a specific clinical interest (e.g. the arm in wheelchair-bound persons). An AM located at the lateral side of the upper leg permits measurement of whole body movement, does not interfere with daily activities, and is the most frequently used site in epidemiological studies [22]. Regarding the type of AM, a review on validity of AMs published between 2000 and 2012 already included 40 different devices [29]. Even a more recent review on the performance of 11 AMs demonstrated a large heterogeneity in outcome with 8 out of the 11 explaining less than $50 \%$ of the variation in activity expenditure compared to the gold standard doubly labelled water method [1].

Nonetheless, accelerometry seems the most promising method for ambulant and objective assessment of physical activity and has demonstrated its superiority to self-report questionnaires and heart rate monitoring [1]. An accelerometer-based AM allows assessment of physical activity in daily life conditions and could provide real-life feedback to facilitate diagnostics, more compliance and behavioral change to recommend or to advise against certain activities in conservative management of knee OA [3, 27]. Furthermore, physical activity has become one of the main determinants of outcome assessment following a total knee replacement (TKR), besides functional capacity tests (e.g. Timed Up and Go test) and self-reported levels of functional 
outcome and satisfaction (i.e. questionnaires), and could provide personalized feedback for more targeted rehabilitation. Although rehabilitation after TKR aims to improve physical activity [30], still an important minority of patients do not improve postoperatively [31]. Due to difficulty in restoring mobility after surgery, patients in rehabilitation after TKR may explore difficulties to be sufficiently physically active to meet guidelines for healthy persons and to return to living independently [23, 32, 33]. It is therefore important to use valid and reliable tools to objectively assess levels of physical activity, to capture specific activity impairments patients encounter in daily life and to set new realistic guidelines for objectively assessed levels of physical activity. Furthermore, longitudinal assessment of physical activity in daily life conditions with an accelerometer, has the potential to provide real-life feedback via graphics and text messages by mobile health care services and could facilitate more compliance and personal rehabilitation after an intervention.

\section{CONCLUSION}

This study demonstrates that an ambulant accelerometerbased physical activity monitor provides a clinically feasible method to objectively assess the four FITT components of physical activity during daily life circumstances in patients with advanced knee OA. Our study results suggest that parameters of physical activity derived by one ambulant triaxial accelerometer can be used as an objective measurement system to supplement self-report questionnaires and provide more insight into the actual physical activity behavior and limitations of knee OA patients in their daily life.

\section{LIST OF ABBREVIATIONS}

$\begin{array}{llll}\text { ADL } & =\text { Activities of Daily LivingAM: Activity } \\ & \text { Monitor } \\ \text { BMI } & =\text { Body Mass Index } \\ \text { DLW } & =\text { Doubly Labeled Water } & \\ \text { FITT } & =\text { Frequency, Intensity, Time, Type } & \\ \text { GCF } & =\text { Gait Cycle Frequency } & \\ \text { OA } & \text { Osteoarthritis } \\ \text { SQUASH } & \text { Short Questionnaire to Assess Health } \\ & \text { enhancing physical activity. } & \\ \text { STS } & =\text { Sit-To-Stand } \\ \text { TKR } & =\text { Total Knee Replacement } & \\ \text { WHO } & =\text { World Health Organization }\end{array}$

\section{CONFLICT OF INTEREST}

The authors confirm that this article content has no conflict of interest.

\section{ACKNOWLEDGEMENTS}

This article represents independent research by the Atrium Heerlen Orthopaedic Research and Scientific Education (AHORSE) Foundation. This research received no specific grant from any funding agency in the public, commercial, or non-profit sectors. The authors declare that this manuscript is original, has not been published before and is not currently being considered for publication elsewhere. The authors declare that there is no conflict of interest. Ethical approval was obtained by the Medical Ethics Committee (METC) of the Atrium Medical Centre Heerlen, The Netherlands, with METC number: 10-N-72.

\section{APPENDIX}

Appendix A: The short questionnaire to assess health enhancing physical activity (SQUASH)

Think about an average week in the past months. Please indicate how many days per week you performed the following activities, how much time on average you were engaged in this, and (if applicable) how strenuous this activity was for you?

\begin{tabular}{|llll|}
\hline $\begin{array}{l}\text { COMMUTING } \\
\text { ACTIVITIES } \\
\text { (round trip) }\end{array}$ & $\begin{array}{l}\text { days } \\
\text { per week }\end{array}$ & $\begin{array}{l}\text { average } \\
\text { time per day }\end{array}$ & $\begin{array}{l}\text { Effort } \\
\text { (circle please) }\end{array}$ \\
$\begin{array}{c}\text { Walking to/from } \\
\text { work or school }\end{array}$ & days & hour minutes & slow/moderate/fast \\
$\begin{array}{c}\text { Bicycling to/from } \\
\text { work or school }\end{array}$ & days & hour minutes & slow/moderate/fast \\
\begin{tabular}{l} 
Not applicable \\
\hline
\end{tabular} & & & \\
\hline
\end{tabular}

\begin{tabular}{|c|c|c|c|}
\hline $\begin{array}{l}\text { LEISURE TIME } \\
\text { ACTIVITIES }\end{array}$ & $\begin{array}{l}\text { days } \\
\text { per week }\end{array}$ & $\begin{array}{l}\text { average time } \\
\text { per day }\end{array}$ & $\begin{array}{l}\text { Effort } \\
\text { (circle please) }\end{array}$ \\
\hline Walking & days & hour minutes & $\begin{array}{l}\text { slow/moderate } \\
\text { /fast }\end{array}$ \\
\hline Bicycling & days & hour minutes & $\begin{array}{l}\text { slow/moderate } \\
\text { /fast }\end{array}$ \\
\hline Gardening & days & hour minutes & $\begin{array}{l}\text { light/moderate } \\
\text { /intense }\end{array}$ \\
\hline Odd jobs & days & hour minutes & $\begin{array}{l}\text { light/moderate } \\
\text { /intense }\end{array}$ \\
\hline $\begin{array}{l}\text { Sports (please write } \\
\text { down yourself) } \\
\text { e.g., tennis, fitness, } \\
\text { skating, swimming, } \\
\text { dancing }\end{array}$ & & & \\
\hline 1. & days & hour minutes & $\begin{array}{l}\text { light/moderate } \\
\text { /intense }\end{array}$ \\
\hline 2. & days & hour minutes & $\begin{array}{l}\text { light/moderate } \\
\text { /intense }\end{array}$ \\
\hline 3. & days & hour minutes & $\begin{array}{l}\text { light/moderate } \\
\text { /intense }\end{array}$ \\
\hline 4 & days & hour minutes & $\begin{array}{l}\text { light/moderate } \\
\text { /intense }\end{array}$ \\
\hline
\end{tabular}

HOUSEHOLD ACTIVITIES days per week average time per day

Light household work days hour minutes

(cooking, washing dishes, days hour minutes ironing, child care)

Intense household work

(scrubbing floor, walking

with heavy shopping bags)

\begin{tabular}{|ll|}
\hline ACTIVITY AT WORK & average time \\
AND SCHOOL & per week \\
Light work & hour minutes \\
(sitting/standing with some walking, e.g., a desk job) & hour minutes \\
Intense work & \\
(regularly lifting heavy objects at work) & \\
Not applicable & \\
\hline
\end{tabular}

\section{REFERENCES}

[1] K.R. Westerterp, "Reliable assessment of physical activity in disease: an update on activity monitors," Curr. Opin. Clin. Nutr. Metab. Care, vol. 17, pp. 401-406, 2014. 
[2] U. Lindemann, W. Zijlstra, K. Aminian, S.F. Chastin, E.D. de Bruin, J.L. Helbostad, and J.B.J. Bussmann, "Recommendations for standardizing validation procedures assessing physical activity of older persons by monitoring body postures and movements," Sensors (Basel), vol. 14, pp. 1267-1277, 2013.

[3] B.H. Dobkin, "Wearable motion sensors to continuously measure real-world physical activities," Curr. Opin. Neurol., vol. 26, pp. 602-608, 2013.

[4] D.D. Dunlop, J. Song, P.A. Semanik, R.W. Chang, L. Sharma, J.M. Bathon, C.B. Eaton, M.C. Hochberg, R.D. Jackson, C.K. Kwoh, W.J. Mysiw, M.C. Nevitt, and J.M. Hootman, "Objective physical activity measurement in the osteoarthritis initiative: Are guidelines being met?," Arthritis Rheum., vol. 63, pp. 3372-3382, 2011.

[5] L. Gonzalez-Villanueva, S. Cagnoni, and L. Ascari, "Design of a wearable sensing system for human motion monitoring in physical rehabilitation," Sensors (Basel), vol. 13, pp. 7735-7755, 2013.

[6] M.M. Vissers, J.B. Bussmann, I.B. de Groot, J.A. Verhaar, and M. Reijman, "Physical functioning four years after total hip and knee arthroplasty," Gait. Posture., vol. 38, pp. 310-315, 2013.

[7] R.J. Shephard, "Limits to the measurement of habitual physical activity by questionnaires," Br. J. Sports Med., vol. 37, pp. 197206; discussion 206, 2003.

[8] J.L. Cavill, J.M. Jancey, and P. Howat, "Review and recommendations for online physical activity and nutrition programmes targeted at over 40s," Glob. Health Promot., vol. 19, pp. 44-53, 2012.

[9] D.K. White, C. Tudor-Locke, D.T. Felson, K.D. Gross, J. Niu, M. Nevitt, C.E. Lewis, J. Torner, and T. Neogi, "Walking to meet physical activity guidelines in knee osteoarthritis: is 10,000 steps enough?," Arch. Phys. Med. Rehabil., vol. 94, pp. 711-717, 2013.

[10] J. Park, I.T. Kazuko, E. Kim, J. Kim, and J. Yoon, "Estimating free-living human energy expenditure: Practical aspects of the doubly labeled water method and its applications," Nutr. Res. Pract., vol. 8, pp. 241-248, 2014.

[11] E. Ravussin, I.T. Harper, R. Rising, and C. Bogardus, "Energy expenditure by doubly labeled water: validation in lean and obese subjects," Am. J. Physiol., vol. 261, pp. E402-E409, 1991.

[12] J.H. Tobias, V. Gould, L. Brunton, K. Deere, J. Rittweger, M. Lipperts, and B. Grimm, "Physical activity and bone: may the force be with you," Front Endocrinol. (Lausanne), vol. 5, p. 20, 2014.

[13] G. Plasqui, A.M. Joosen, A.D. Kester, A.H. Goris, and K.R. Westerterp, "Measuring free-living energy expenditure and physical activity with triaxial accelerometry," Obes. Res., vol. 13, pp. 1363-1369, 2005.

[14] I.B. de Groot, J.B. Bussmann, H.J. Stam, and J.A. Verhaar, "Actual everyday physical activity in patients with end-stage hip or knee osteoarthritis compared with healthy controls," Osteoarthritis Cartilage, vol. 16, pp. 436-442, 2008.

[15] S.J. Preece, J.Y. Goulermas, L.P. Kenney, D. Howard, K. Meijer, and R. Crompton, "Activity identification using body-mounted sensors--a review of classification techniques," Physiol. Meas., vol. 30, pp. R1-33, 2009.

[16] M.J. Mathie, B.G. Celler, N.H. Lovell, and A.C. Coster, "Classification of basic daily movements using a triaxial accelerometer," Med. Biol. Eng. Comput., vol. 42, pp. 679-687, 2004.

[17] L.C. Masse, B.F. Fuemmeler, C.B. Anderson, C.E. Matthews, S.G. Trost, D.J. Catellier, and M. Treuth, "Accelerometer data reduction: a comparison of four reduction algorithms on select outcome variables," Med. Sci. Sports Exerc., vol. 37, pp. S544-S554, 2005.

[18] M. Kang, P.D. Hart, and Y. Kim, "Establishing a threshold for the number of missing days using $7 \mathrm{~d}$ pedometer data," Physiol. Meas., vol. 33, pp. 1877-1885, 2012.

[19] G.C. Wendel-Vos, A.J. Schuit, W.H. Saris, and D. Kromhout, "Reproducibility and relative validity of the short questionnaire to assess health-enhancing physical activity," J. Clin. Epidemiol., vol. 56, pp. 1163-1169, 2003.
[20] R. Wagenmakers, I. van den Akker-Scheek, J.W. Groothoff, W. Zijlstra, S.K. Bulstra, J.W. Kootstra, G.C.W. Wendel-Vos, J-J. van Raaij, and M. Stevens, "Reliability and validity of the short questionnaire to assess health-enhancing physical activity (SQUASH) in patients after total hip arthroplasty," BMC Musculoskelet. Disord., vol. 9, p. 141, 2008.

[21] A.M. Davis, A.V. Perruccio, M. Canizares, G.A. Hawker, E.M Roos, J.F. Maillefert, and L.S. Lohmander, "Comparative, validity and responsiveness of the HOOS-PS and KOOS-PS to the WOMAC physical function subscale in total joint replacement for osteoarthritis," Osteoarthritis Cartil., vol. 17, pp. 843-847, 2009.

[22] J.N. Farr, S.B. Going, T.G. Lohman, L. Rankin, S. Kasle, M. Cornett, and E. Cussler, "Physical activity levels in patients with early knee osteoarthritis measured by accelerometry," Arthritis Rheum., vol. 59, pp. 1229-1236, 2008.

[23] J.A. Wallis, K.E. Webster, P. Levinger, and N.F. Taylor, "What proportion of people with hip and knee osteoarthritis meet physical activity guidelines? A systematic review and meta-analysis," Osteoarthritis Cartil., vol. 21, pp. 1648-1659, 2013.

[24] M.F. Pisters, C. Veenhof, G.M. van Dijk, J. Dekker, and C.S Group, "Avoidance of activity and limitations in activities in patients with osteoarthritis of the hip or knee: a 5 year follow-up study on the mediating role of reduced muscle strength," Osteoarthritis Cartilage, vol. 22, pp. 171-177, 2014.

[25] F. Dobson, R.S. Hinman, E.M. Roos, J.H. Abbott, P. Stratford, A.M. Davis, R. Buchbinder, L. Snyder-Mackler, Y. Henrotin, J. Thumboo, P. Hansen, and K.L. Bennell., "OARSI recommended performance-based tests to assess physical function in people diagnosed with hip or knee osteoarthritis," Osteoarthritis Cartilage, vol. 21, pp. 1042-1052, 2013.

[26] K.P. Dowd, D.M. Harrington, A.K. Bourke, J. Nelson, and A.E. Donnelly, "The measurement of sedentary patterns and behaviors using the activPAL professional physical activity monitor," Physiol. Meas., vol. 33, pp. 1887-1899, 2012.

[27] E. Vignon, J.P. Valat, M. Rossignol, B. Avouac, S. Rozenberg, P. Thoumie, J. Avouac, M. Nordin, and P. Hilliquin, "Osteoarthritis of the knee and hip and activity: a systematic international review and synthesis (OASIS)," Joint Bone Spine, vol. 73, pp. 442-455, 2006.

[28] A. Holsgaard-Larsen, and E.M. Roos, "Objectively measured physical activity in patients with end stage knee or hip osteoarthritis," Eur. J. Phys. Rehabil. Med., vol. 48, pp. 577-585, 2012.

[29] H. Van Remoortel, S. Giavedoni, Y. Raste, C. Burtin, Z. Louvaris, E. Gimeno-Santos, D. Langer, A. Glendenning, N.S. Hopkinson, I. Vogiatzis, B.T. Peterson, F. Wilson, B. Mann, R. Rabinovich, M.A Puhan, T. Troosters, and PROactive consortium, "Validity of activity monitors in health and chronic disease: a systematic review," Int. J. Behav. Nutr. Phys. Act., vol. 9, p. 84, 2012.

[30] C.L. Peiris, N.F. Taylor, and N. Shields, "Patients receiving inpatient rehabilitation for lower limb orthopaedic conditions do much less physical activity than recommended in guidelines for healthy older adults: an observational study," J. Physiother., vol. 59, pp. 39-44, 2013.

[31] A.D. Beswick, V. Wylde, R. Gooberman-Hill, A. Blom, and P. Dieppe, "What proportion of patients report long-term pain after total hip or knee replacement for osteoarthritis? A systematic review of prospective studies in unselected patients," BMJ Open, vol. 2, p. e000435, 2012.

[32] J.W. Groen, M. Stevens, R.F. Kersten, I.H. Reininga, and I. van den Akker-Scheek, "After total knee arthroplasty, many people are not active enough to maintain their health and fitness: an observational study," J. Physiother., vol. 58, pp. 113-116, 2012.

[33] M. Brandes, M. Ringling, C. Winter, A. Hillmann, and D. Rosenbaum, "Changes in physical activity and health-related quality of life during the first year after total knee arthroplasty," Arthritis Care Res. (Hoboken), vol. 63, pp. 328-334, 2011. 